\title{
EVALUATION OF SUPPLIERS AT A STEEL STRUCTURE MANUFACTURER
}

\author{
Katalin KELLER ${ }^{1}$, Balázs KOCSI, István BUDAI \\ University of Debrecen, Faculty of Engineering, Department of Engineering Management and Enterprises, \\ Debrecen, Hungary \\ ${ }^{1}$ kata51931@gmail.com
}

\begin{abstract}
In today's world, where competition is becoming increasingly prominent, companies need to focus on several aspects in order to be successful in their operations. Purchasing is essential to achieving this goal, so suppliers can be evaluated as well. A new approach is created based on the QFD method for evaluating suppliers, which can be quickly and easily performed, even without the help of a computer. This method was tested in a company based in a North Eastern Hungarian city. Firstly, suppliers were selected by ABC analysis and then the expectations were defined and compared based on the order of their preference matrix. The three categories were A, B and C, one supplier achieved a place in the best category, two suppliers a place in the second category, five suppliers joined the third category. Furthermore, Suppliers were categorized by Kraljic matrix. The supplier rating which was based on the QFD (Quality Function Deployment) method, allows analysis of the performance of a given supplier in an easy way within the company and to develop them over the longterm in order to make the company more successful based on the results of combined work.
\end{abstract}

Keywords: supplier rating, QFD, supplier characterization number.

\section{Introduction}

An essential factor in the success of a company is well-functioning logistics within that company. Logistics is a part of the supply chain, which aims at planning, executing and controlling the flows of raw materials, semi-processed product and processed product as well as information from the place of their origin to the place of use with the intention of meeting the customer expectations in a cost-efficient way [1]. The aim of logistics is to deliver the appropriate product to the customer in the appropriate time and at an appropriate cost. The literature distinguishes 4 different fields of logistics: procurement, production logistics, distribution, and last, but not least, recycle logistics. The main duties of procurement are to provide access to all the necessary raw materials, carrier materials, fuel, spare parts and fittings, in the appropriate quantity, quality, time, place at the appropriate costs, that is, procurement is responsible for material flow connected to material supplies as well as the planning, organizing, managing and supervising of all the relevant information flow [2]. Due to this, procurement has become indispensable in the life of the companies. Therefore, it is essential to evaluate the performance of the suppliers. There are many supplier rating methods, for example the Kraljic-matrix or weighted points system. In addition, the Quality Function Deployment method (hereinafter QFD) is also applicable for this issue. According to Bessert's opinion, QFD is a strictly structured methodology for integrated product development as well as product improvement, which proves to be necessary when the market share of a product starts to decrease comparing to its competitors [3]. 


\section{Objectives}

The first book addressing Quality Function Deployment was published by Dr. Akao and Dr. Shigeru Mizuno. The definition of QFD according to the inventors is as follows: QFD is a methodology that transforms customer requirements into quality features, determines the design quality of the final product, and this quality is systematically applied to the quality of the components, parts, elements of the process, and all the connections between them [4]. QFD can help to rank the customers' requirements and identify multifunctional groups. Furthermore, this method aids connecting these requirements with the features of the relevant service or product [5] [6]. A study of supplier rating with the use of the QFD method was published by Angela Tidwell and J. Scott Sutterfield. This paper serves as a basis of the methodology improvement of this research. The modified method can be executed quicker and easier, and it can be accomplished without the help of computers. This method also takes both quantitative and qualitative factors into account.

\section{The presentation of the modified method}

In order to make the model more realistic and accurate, a lot of measures had to be taken. As a first step, the QFD method - which is used for supplier rating - was improved. In the second step, a large project was selected in the examined company in order to perform the analysis. This project was a construction of a hall made with steel. After this, suppliers were collected and methodized, in order to check their contributions to the project. These suppliers were put into 3 categories: A, B and $\mathrm{C}$, which indicates the rank of important suppliers in a given project. Then, requirements were set for the suppliers. Following this, these requirements were ranked with the use of a preference matrix, which helps to reveal the most important requirements for the company.

By using a preference matrix, different conditions can be compared regarding the company's preferences, and an order can be created, which represents the company's requirements. In the next step, data collection was carried out, which was necessary to reveal how particular suppliers can satisfy these requirements. Points were assigned to the suppliers in order to evaluate how these different requirements prevail at the suppliers. These values were the following: 1, 3 and 9 .
Value 1 indicates weak, value 3 stands for average, while value 9 is a strong value. These numbers show the presence of criteria in a value system, performance and capability of a supplier. Values of all conditions were then accumulated for each supplier. In this way, every supplier received a final value: the Supplier Characterization Number:

$$
S C N=\sum_{i=1}^{n} S v_{i} W_{i}
$$

where

$S C N=$ Supplier Characterization Number

$S v_{i}=$ Supplier value for requirement $\mathrm{i}$

$W_{i}=$ Weight belonging to requirement $\mathrm{i}$

In the last phase, suppliers were categorized into A, B and C categories. Those suppliers achieving the „A" category, are those which are good enough for the company to work with in the near future. The examined company would expect improvement to those suppliers who are in the „B” category. Finally, those suppliers, which were in the „C” category, had performed poorly, and therefore need rapid improvement in order to keep the work relationship with the examined company. The last phase of the work was the categorization of the suppliers according to Kraljic matrix. With the application of this method, the conformity of the relationship was determined between the company and a supplier.

\section{Results}

In the given project, suppliers were put into A, $\mathrm{B}$ and $\mathrm{C}$ categories. According to the order, the first 8 were selected from the total 15 suppliers, because these suppliers had the most significant role in the output of the project. These 8 suppliers were categorized in accordance with Kraljic-matrix. In the leverage category there are two suppliers:

- Supplier 3

- Supplier 6.

The non-critical category consists of the following suppliers:

- Supplier 2.

- Supplier 4.

The strategic category included the remaining suppliers:

- Supplier 1.

- Supplier 5.

- Supplier 7.

- Supplier 8.

None of the suppliers fell into the bottleneck category. Requirements for the suppliers were 
ranked with the use of the preference matrix. In the next step, performances of the suppliers were evaluated in terms of each requirement. The maximum achievable value was 945 , if a supplier could fulfil all the requirements in the best possible way. This value was not achieved by any of the suppliers. However, there was one company which approached that level. Supplier 1 achieved the highest value, this was 853 .

The performed ABC-analysis can be seen in Table 1.

In Table 2. we can see the summary of the requirements regarding each supplier that need to be satisfied before a deadline. In the table, those suppliers, whose deadlines are indicated in red were granted time extension by the company until a set date for further improvement. In the case that this improvement is not carried out, cooperation will be terminated, and these suppliers will be excluded in the future. This decision is also supported by the fact that they were put in the noncritical category on the basis of the Kraljic-matrix. Therefore, their products can be easily procured, and do not play a strategical role, (if the suppliers are not able to develop and correct their mistakes), because the company can find another supplier for that product without difficulty for future cooperation.

\section{Conclusion}

The modified method can be applied to every project in the supplier selection phase in order to get the best output from the project. With the application of this method, calculations and selections become easier to carry out, even with the use of a paper and a pen. This method can rank the suppliers, while it highlights the path of the improvement. This is an essential part of the rela-

Table 1. Categorization of the suppliers according to $A B C$-analysis

\begin{tabular}{|c|c|c|c|c|}
\hline Suppliers & Value & Value $\%$ & Cum $\%$ & Cat. \\
\hline Supplier 1. & 853 & $15.23 \%$ & $15,23 \%$ & $\mathrm{~A}$ \\
\hline Supplier 4 & 807 & $14.41 \%$ & $29,64 \%$ & $\mathrm{~B}$ \\
\hline Supplier 2 & 767 & $13,70 \%$ & $43,34 \%$ & $\mathrm{~B}$ \\
\hline Supplier 5 & 661 & $11,80 \%$ & $55,14 \%$ & $\mathrm{C}$ \\
\hline Supplier 8 & 645 & $11,52 \%$ & $66,66 \%$ & $\mathrm{C}$ \\
\hline Supplier 7 & 633 & $11,30 \%$ & $77,96 \%$ & $\mathrm{C}$ \\
\hline Supplier 3 & 631 & $11,27 \%$ & $83,23 \%$ & $\mathrm{C}$ \\
\hline Supplier 6 & 603 & $10,77 \%$ & $100,00 \%$ & $\mathrm{C}$ \\
\hline
\end{tabular}

tionship, because working together is a strategic issue for both suppliers and the company. This method is able to determine the most suitable supplier group for the company.

In order to produce the best quality product or provide the best service, it is essential for the company to obtain the appropriate raw material within the appropriate time and at an appropriate cost. Thus, selection of the best suppliers for the company plays a key role in the life of the companies. This modified QFD method serves as an excellent tool for this aim.

\section{Acknowledgement}

The work is supported by the EFOP-3.6.1-16-201600022 project. The project is cofinanced by the European Union and the European Social Fund.

\section{References}

[1] Kovács L.: Logisztika. Pannon Egyetemi Kiadó, Veszprém, 2004, 2.

[2] Cselényi J., Illés B., Bányainé T. Á., Bányai T., Kovács L., Mang B., Németh J.: Logisztikai rendszerek I. Miskolci Egyetemi Kiadó, 2009, 47.

[3] Bossert J. L.: Quality Function Deployment: A Practitioner's Approach. American Society of Quality Control (ASQC), Qualitiy Press, Milwaukee, Wi, 1991.

[4] Akao Y.: History of Quality Function Deployment in Japan. The Best on Quality, IAQ Book Series 3. International Academy for Quality, 1990, 183-196.

[5] Krieg R. : Impact of structured product definition on market success. The International Journal of Quality \& Reliability Management, 21/9. (2004) 991-1002.

https://doi.org/10.1108/02656710410561808

Table 2. Categorization of the suppliers according to Kraljic-matrix

\begin{tabular}{|c|c|c|c|}
\hline Suppliers & $\begin{array}{c}\text { Nr. of } \\
\text { im- } \\
\text { prover } \\
\text { actions }\end{array}$ & Deadline & Category \\
\hline Supplier 1. & 0 & - & Strategic \\
\hline Supplier 4 & 3 & 25.11 .2017 & Leverage \\
\hline Supplier 2 & 2 & 31.12 .2017 & Leverage \\
\hline Supplier 5 & 3 & 15.04 .2017 & Strategic \\
\hline Supplier 8 & 1 & 21.12 .2017 & Strategic \\
\hline Supplier 7 & 3 & 12.02 .2017 & Strategic \\
\hline Supplier 3 & 2 & 29.11 .2017 & Non-critical \\
\hline Supplier 6 & 2 & 27.11 .2017 & Non-critical \\
\hline
\end{tabular}


[6] Kaufmann L., Michel A., Carter C. : Debiasing strategies in supply management decision-making. Journal of Business Logistics, 30/1. (2009) 85-106.

https://doi.org/10.1002/j.2158-1592.2009. tb00100.x 